XX. Bemerkungen, ceranlafst durch den Aufsalz des Hrn. Broch über die Fraunhoferschen Linien;

(Briefliche Mithieilung von Hrn. Dr. L. Merz.)

Müncben, den 18. Felor. 1852.
- Gestatten Sie gütigst folgende kurze Berichtigung. Im Ergänzungsband III Stück 2, S. 312 Ihrer Annalen findet sich in Bezug auf Prismen von gleicher Reinheit als die von Fraunhofer verfertigten folgende Acufserung des Hrn. Broch in Christiania: "So weit mir bekannt, bedient man sich noch immer der von diesem ausgezeichneten Künstler und Naturforscher hinterlassenen Glasmassen, wenn von seinen Nachfolgern in München ein besonders feines optisches Instrument verfertigt werden soll."

Hierauf erlauben wir uns zu erwiedern: Alles brauchbare Glas, welches das optische Institut in keiner bedeutenden Quantität noch aus der Zeit des unvergefslichen Fraunh ofer besitzt, hat für dasselbe einen grofsen historischen Werth, und wird sorgfältig aufbewahrt, ohne dafs ein Stückchen davon verwendet würde. Seit Fraunhofer's Tode sind daselbst schon viele Schmelzen gemacht, reines, auch von den feinsten Wellen freies Glas in noch grölseren Dimensionen erzeugt, und eine Menge von Prismen und Objectiven verschiedener Gröfse mit unbestritte. ner Vollkommenheit geschliffen worden. Eins der grüfseren Prisinen, welche ganz von Fraunhofer's Nach. folgern gefertigt wurden, hat unter andern Sir David Brewster erhalten und damit seine besten Beobachtungen angestellt. Alle Naturforscher, welche das Institut besuchten, und die Prismen aus Fraunhofer's Zeit mit den späteren verglichen haben, nahmen die Ueberzeugung mit sich, dafs die letzteren, theilweise, trotz gröfserer Brechungskraft, noch weifser, reiner und vollkommener denn die ersteren sind. Es ist somit die etwaige Befürchtung, dafs nach dem Ausgehen der Fraunhofer'schen Glasmassen 
die Physiker nicht mehr mit ganz vollkommenen Prismen versorgt werden könnten, völlig unbegründet.

Was nun den weiteren Inhalt der Abhandlung des Hrn. Broch betrifft, so stimmen wir mit ihm darin überein, dafs die Zeichnungen des Spectrums in den meisten Lehrbüchern ganz ungenügend sind. Die beste ist, nach der Originalzeichnung F raunbofer's (Denkschr. d. Ac. z. M. 1814 u. 15), jene in Baumgartner's Supplementband. Die eigenthümlichste scheint dic des Hrn. Broch selbst; wenigstens haben wir noch nie die Parthie bei $D$, und jene zwischen $G$ und $H$ so gesehen, wie er sie zeichnet. Damit wollen wir nicht unbedingt sagen, dafs sie irrig gemacht sey, vielınehr erweckt sie in uns noch stärker den schon früher geäufserten Wunsch, dals an sehr verschiedemen Standorten, auf Höhen, an Meere u. s. w. die Spectrunsbeobachtungen wiederholt werden mögen. Zwar konnten wir aus unseren Beobachtungen dahier und den von Mossotti in Pisa gemachten keinen auffallenden Unterschied entnehmen; allein die Atmosphäre an der Nordsee, im Gegensatz zu jener am Mittelmeere, mag schon gröisere Unterschiede zulassen. Nicht unbeachtet darf bleiben, dafs Hr. Broch seine Beobachtungen in den Morgen- und Abendstunden machte, was nach den gewichtigen Versuchen von Prof. Kuhn (Ann. 1818 II.) und nach unseren eigenen Wahrnehmungen von wesentlichem Einflufs ist, doch nicht in dem Grade, dafs es die in der Zeichnung des Hrn. B roch bemerkten Modificationen herbeiführen könnte. Der Vergleich ferner, welchen Hr. Broch zwischen dem polarisirten und dem Spectrumslicht anstellt, scheint uns bei der verschiedenen Natur beider keinen ganz sicheren Schlufs auf Analogie zuzulassen. Doch dürfte es lohnend seyn, wenn Gelehrte, welche hinreichende Mufse dazu fänden, diese Vergleichung fortfübren würdell, mehr noch, wenn sie jene mit dem normalen Gitterspectrum, wie sie Moss otti (sulle proprietà degli spettri di Fraunhofer, Pisa 1845, auch in diesen Annalen 1847, 12 wiedergegeben) so weit es die bisherigen photometri- 
schen Leistungen gestatteten, mit mathematischer Klarheit durchgeführt hat, noch weiter verfolgen würden.

Erlauben Sie noch eine andere Bemerkung. Der Biehauptung des Hrn. Prof. Ragona-Scina, als entständen Longitudinallinien nicht von Unregelmäfsigkeiten im Spalte des Heliostates, müssen wir aus eigener Erfahrung widersprechen, und damit stimmen auch die HH. Knoblauch, Kuhn und Lamont überein. Man wird überhaupt beim Spectrum dasjenige unterscheiden müssen, was der Refraction und Dispersion angehört, und was der Inflexion und Interferenz zuzuschrciben ist. Dafs Ungleichheiten des Spaltes, wie des Spiegels, Beugung und Interferenz des Lichtes hervorrufen können, ist durch viele Versuche dargethan; dafs aber das Experiment mit der Linse auch eine Interferenz bewirkt, widerspricht ja keineswegs jenen früheren Versuchen. Wir haben uns somit noch keineswegs überzeugen können, dafs die Longitudinallinien der Natur des vom Prisma allein alterirten Lichtes inhäriren ').

\section{Nachschrift zum Aufsatze: Beobachtungen über Zerstreuungsbilder im Auge und über die Theorie des Sehens; con Dr, Fliedner.}

Die Sätze der Nr. 20 (S. 344) bedürfen noch einer Ergänzung. Sie lassen dic Frage über die Adaption des Auges ganz unberührt und könnten, wie ich nachträglich eingesehen habe, zu der Meinung führen, ich nehme einen bleibenden Refractionszustand des Auges bei Fixirung eines sich fortbewegenden Gegenstandes an. Dafs aber ein solcher nicht stattfindet, davon kann man sich durch folgende einfache Beobachtungen überzeugen:

Bringt man die Scheibe und eine Nadel vor derselben in dic deutliche Selıweite, läfst die Nadel unverrückt ste1) Vergl. S, 364 dicses Hefts. $\boldsymbol{P}$. 